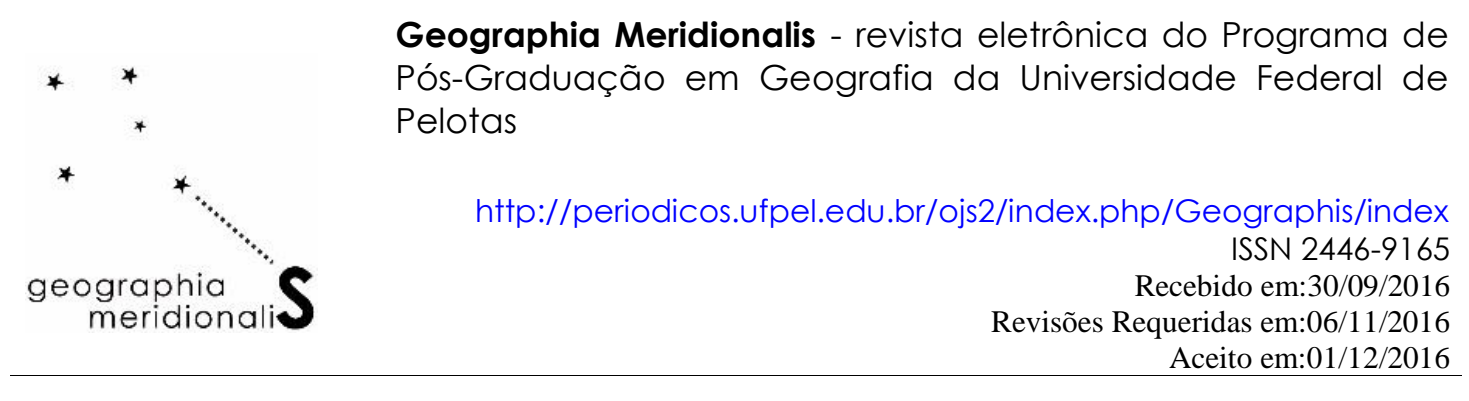

\title{
DELIMITAÇÃO E CARACTERIZAÇÃO AMBIENTAL DO BANHADO DO PONTAL DA BARRA, PELOTAS, RS (PARTE I): PORÇÃO LESTE
}

\author{
Giovanni Nachtigall Maurício \\ Grupo Especial de Estudo e Proteção do Ambiente Aquático do Rio Grande do Sul \\ Setor de Ictiologia, Divisão de Fauna \\ Universidade Federal de Pelotas \\ Curso Superior de Tecnologia em Gestão Ambiental \\ gnachtigallmauricio@yahoo.com.br \\ Tiago Schuch Lemos Venzke \\ Ecólogo, Doutorando do Programa de Pós-Graduação em \\ Manejo e Conservação do Solo e da Água (PPG-MACSA) \\ venzke.tiago@gmail.com
}

\section{1 - Introdução}

O Pontal da Barra, na praia do Laranjal, Pelotas-RS, tem recebido atenção em razão da expansão imobiliária sobre áreas úmidas e dos resultantes impactos ambientais (SELMO; ASMUS, 2006; SILVA et al. 2015). Nesse contexto, o fato mais relevante é o aterramento de zonas de banhado (denominação regional para um tipo de área úmida, equivalente a brejo) para a expansão do loteamento do Pontal da Barra, situação que chamou a atenção tanto do meio acadêmico quanto da população em geral, especialmente porque as obras tinham licença ambiental emitida pela Fundação Estadual de Proteção Ambiental Henrique Luiz Roessler - FEPAM (MILHEIRA et al., 2012). Em grande parte, a importância do Pontal da Barra baseia-se em dois pilares: riqueza de sítios arqueológicos e elevada biodiversidade. Em termos de arqueologia destaca-se o grande número de cerritos indígenas, num total de 18 (MILHEIRA et al., 2012). Quanto à biodiversidade, destaca-se a ocorrência de várias espécies ameaçadas de extinção, fato que gerou numerosas recomendações para a conservação da área (FONTANA et al. 2003). Entre as espécies ameaçadas merecem destaque Austrolebias nigrofasciatus e Austrolebias wolterstorffi, ambos oficialmente considerados ameaçados de extinção em nível nacional (Portaria $n^{\circ} 445 / 2014$ do Ministério do Meio Ambiente) (BRASIL, 2014) e estadual (Decreto Estadual $n^{\circ}$ 51.797, de 08 de setembro de 2014) (RIO GRANDE DO SUL, 2014). 
Um dos pontos mais relevantes em termos de patrimônio ambiental e científico está no fato do Pontal da Barra ser a localidade-tipo de Austrolebias nigrofasciatus. A localidadetipo de uma espécie é o lugar geográfico de captura, coleta ou observação do "tipo portador do nome” (ICZN [International Commission on Zoological Nomenclature] 1999). O tipo portador do nome é o exemplar (ou conjunto de exemplares) que serviu de base para a descrição e nomeação formal de uma espécie nova para a ciência; essa nomeação formal é o momento em que o nome científico é pela primeira vez publicado, no sentido estabelecido pelo Código Internacional de Nomenclatura Zoológica e tendo, necessariamente, atendido a todos os demais critérios aplicáveis e em vigência desse código (ICZN, 1999). Para A. nigrofasciatus, o "tipo portador do nome" foi coletado em um trecho do banhado do Pontal da Barra, assim como todos os demais espécimes da série-tipo (COSTA; CHEFFE, 2001). Uma vez que A. nigrofasciatus só ocorre em banhados e charcos temporários, sendo incapaz de cruzar grandes volumes de água, o canal São Gonçalo e o arroio Pelotas representam barreiras geográficas potenciais à sua dispersão (vide figura 1). Portanto, pode-se assumir que somente a população do Pontal da Barra (os topótipos da espécie) pode ser identificada com segurança como $A$. nigrofasciatus, fato que reveste essa localidade de grande importância científica e ambiental.

Figura 1 - Contextualização espacial da área de estudo

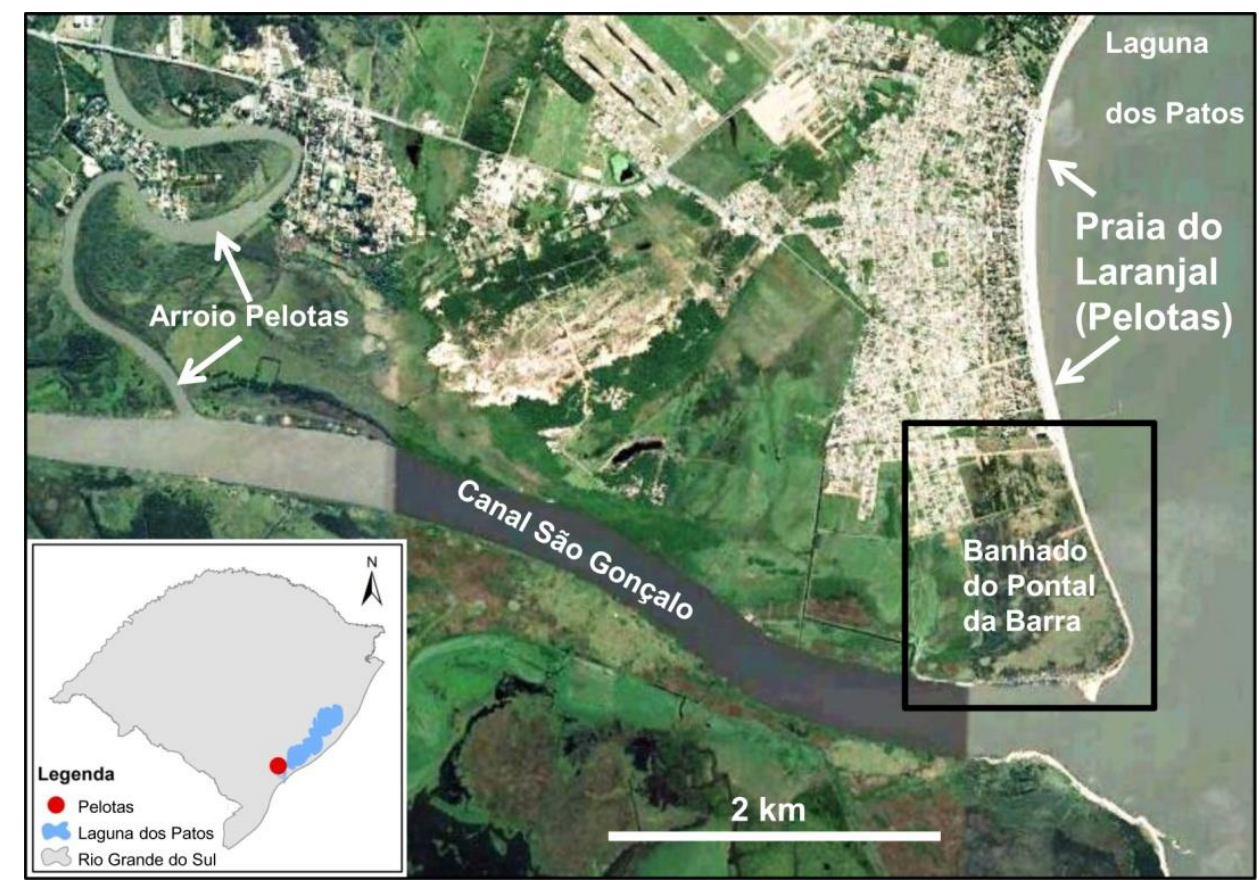

Principais localidades e corpos d'água mencionados no texto (município de Pelotas). O retângulo delimita a área detalhada na figura 2. Fonte: Google Earth (editado pelos autores). 
Uma controvérsia que envolve o Pontal da Barra e a conservação dos peixes anuais é a delimitação das áreas de banhado. O EIA-RIMA do Pontal da Barra (EIA [Estudo de Impacto Ambiental], 1990), feito com vistas a obter licença ambiental para instalação de loteamento residencial na área, mencionou que os banhados devem ser preservados, mas não aportou nenhum mapa para delimitá-los. Tal lacuna foi sanada posteriormente ao EIA-RIMA, com a apresentação de um mapeamento (1993) no qual foi ilustrada uma delimitação para a área de banhado. Contudo, a delimitação aludida qualificou como esse ambiente uma área muito restrita, deixando grande parte do extenso banhado do Pontal da Barra qualificado ora como campo limpo, ora como campo inundável. Essa deficiência resultou em licenciamento sobre áreas de banhado strictu sensu, gerando aterramento e degradação de áreas que deveriam ser de preservação permanente (MINISTÉRIO PÚBLICO FEDERAL, 2012).

Portanto, a presente nota técnica visa contribuir para a delimitação e caracterização ambiental da área de banhado do Pontal da Barra, em sua porção leste, estabelecendo critérios científicos para tal delimitação. Em outra contribuição serão delimitados os banhados da porção oeste da área.

\section{2 - Desenvolvimento}

Para a delimitação e caracterização do que seria o ambiente denominado "banhado", empregaram-se critérios previamente existentes e adicionou-se novos. Em primeiro lugar, tomou-se a definição de banhado constante no Código Estadual do Meio Ambiente, Lei n 11.520 (RIO GRANDE DO SUL, 2000), que estabelece: "banhados: extensões de terras normalmente saturadas de água onde se desenvolvem fauna e flora típicas”. Em segundo lugar, tomou-se a definição de banhado constante no Decreto Estadual 52.431, que dispõe sobre a implementação do Cadastro Ambiental Rural (RIO GRANDE DO SUL, 2015) trazendo, em seu artigo $6^{\circ}$, a seguinte definição e critérios:

Para fins de cadastramento dos imóveis rurais no CAR, consideram-se Banhados (inc. XIV do art. 14, inc. VII do art. 51 e inc. VI do art. 155, todos da Lei $\mathrm{n}^{\mathrm{o}} 11.520$, de 3 de agosto de 2000) as extensões de terra que apresentem de forma simultânea as seguintes características:

I - solos naturalmente alagados ou saturados de água por período não inferior a 150 dias ao ano, contínuos ou alternados, excluídas as situações efêmeras, as quais se caracterizam pelo alagamento ou saturação do solo por água apenas durante ou imediatamente após os períodos de precipitação.

II - ocorrência espontânea de no mínimo uma das espécies de flora típica abaixo relacionadas: 
a) Junco (Schoenoplectus spp., Juncus spp.); b) Aguapé (Eichhornia spp.); c) Erva-de-Santa-Luzia ou marrequinha (Pistia stratiotes); d) Marrequinha-doBanhado (Salvinia sp.); e) Gravata ou caraguatá-de-banhados (Eryngium pandanifolium); f) Tiririca ou palha-cortadeira (Cyperus giganteus); g) Papiro (Cyperus papyrus); h) Pinheirinho-da-água (Myriophyllum brasiliensis); i) Soldanela-da-água (Nymphoides indica); j) Taboa (Typha domingensis); k) Chapeu-de-couro (Sagittaria montevidensis); e l) Rainha-das-lagoas (Pontederia lanceolata).

Parágrafo único. A ocorrência regular de uma ou mais das espécies da fauna abaixo relacionadas auxilia na caracterização de banhados:

a) Jacaré-de-papo-amarelo (Caiman latirostris); b) Tachã (Chauna torquata); c) Garça-branca-grande (Ardea alba); d) Frango-d'água (Gallinula spp.); e) Caramujo ou aruá-do-banhado (Pomacea canaliculata); f) Gavião-caramujeiro (Rostrhamus sociabilis); g) Jaçanã (Jacana jacana); h) Marreca-de-pévermelho (Amazonetta brasiliensis); i) Cardeal-do-banhado (Amblyramphus holosericeus); j) João-grande (Ciconia maguari); k) Nútria ou ratão-dobanhado (Myocastor coypus); e 1) Capivara (Hydrochoerus hydrocoerus).

Em terceiro lugar, visto que a definição de "fauna típica" (como constante no Código Estadual do Meio Ambiente) é um tanto vaga, buscou-se entre a fauna aquelas espécies que poderiam ser indicadores fiéis do ambiente "banhado". Assim, uma vez que os peixes anuais A. nigrofasciatus e A. wolterstorffi só ocorrem em banhados e charcos temporários (CHEFFE et al., 2016), ambas espécies podem ser consideradas indicadores confiáveis da presença de banhados, cabendo adicionar que os charcos temporários, igualmente, se enquadram na definiçãa de banhado do Código Estadual do Meio Ambiente e do Cadastro Ambiental Rural. Entre as aves, Limnornis curvirostris (joão-da-palha) ocorre exclusivamente em banhados cobertos com juncais e palha, sempre em áreas com lâmina d'água permanente ou semipermanente. Essa espécie é endêmica dos banhados do bioma Pampa, sendo tomada aqui como um indicador apropriado da presença de banhado.

Em relação à flora, uma espécie ameaçada de extinção e característica de banhados é Zizaniopsis bonariensis (Balansa \& Poitr.) Speg. A espécie possui o nome popular de “espadana” e pertence à família botânica das Poaceae (gramíneas). Essa espécie pertence ao grupo das plantas denominadas de macrófitas aquáticas e que habitam áreas úmidas como o ecossistema de banhados. As macrófitas aquáticas são vegetais visíveis a olho nu, cujas partes fotossintetizantes estão permanentemente, ou por diversos meses do ano, total ou parcialmente submersas em água doce ou salobra, ou ainda flutuante na mesma (IRGANG; GASTAL JR., 1996). Zizaniopsis bonariensis é uma macrofita aquática boa bioindicadora de áreas úmidas e a sua dinâmica de ocorrência é afetada por fatores hidrológicos como a profundidade de água e a associação com a duração e sazonalidade da inundação (TASSI et al, 2007). Esta espécie é rara no estado do Rio Grande do Sul. Em nível nacional, segundo a lista oficial de espécies da flora ameaçadas de extinção do 
Brasil, Zizaniopsis bonariensis é classificada na categoria de "Em Perigo" (BRASIL, 2014).

Para uma avaliação mais detalhada, definiram-se nove (9) setores no banhado do Pontal da Barra, conforme a figura 2. Esses setores foram amostrados em fases distintas. Primeiramente, trabalhos de campo sobre a fauna foram conduzidos ao longo de toda a área entre os anos de 1987 e 2002, com periodicidade semanal. Numa segunda fase, a área foi amostrada entre 2012 e 2016, com periodicidade mensal. Os registros da segunda fase foram tomados a partir da margem de ruas / aterros que cortam o banhado. A observação das espécies da flora foi realizada pelo método de caminhamento nos diferentes setores demarcados no Pontal da Barra, em 2015 e 2016 (Figura 2). Foram listadas plantas de fácil visualização e comuns no local (Tabela 1). As plantas observadas foram identificadas com conhecimento de campo da equipe e por consulta a material bibliográfico especializado (CORDAZZO; SEELIGER, 1995; IRGANG; GASTAL, 1996; CORDAZZO et al., 2006).

Figura 2 - Setores do banhado do Pontal da Barra

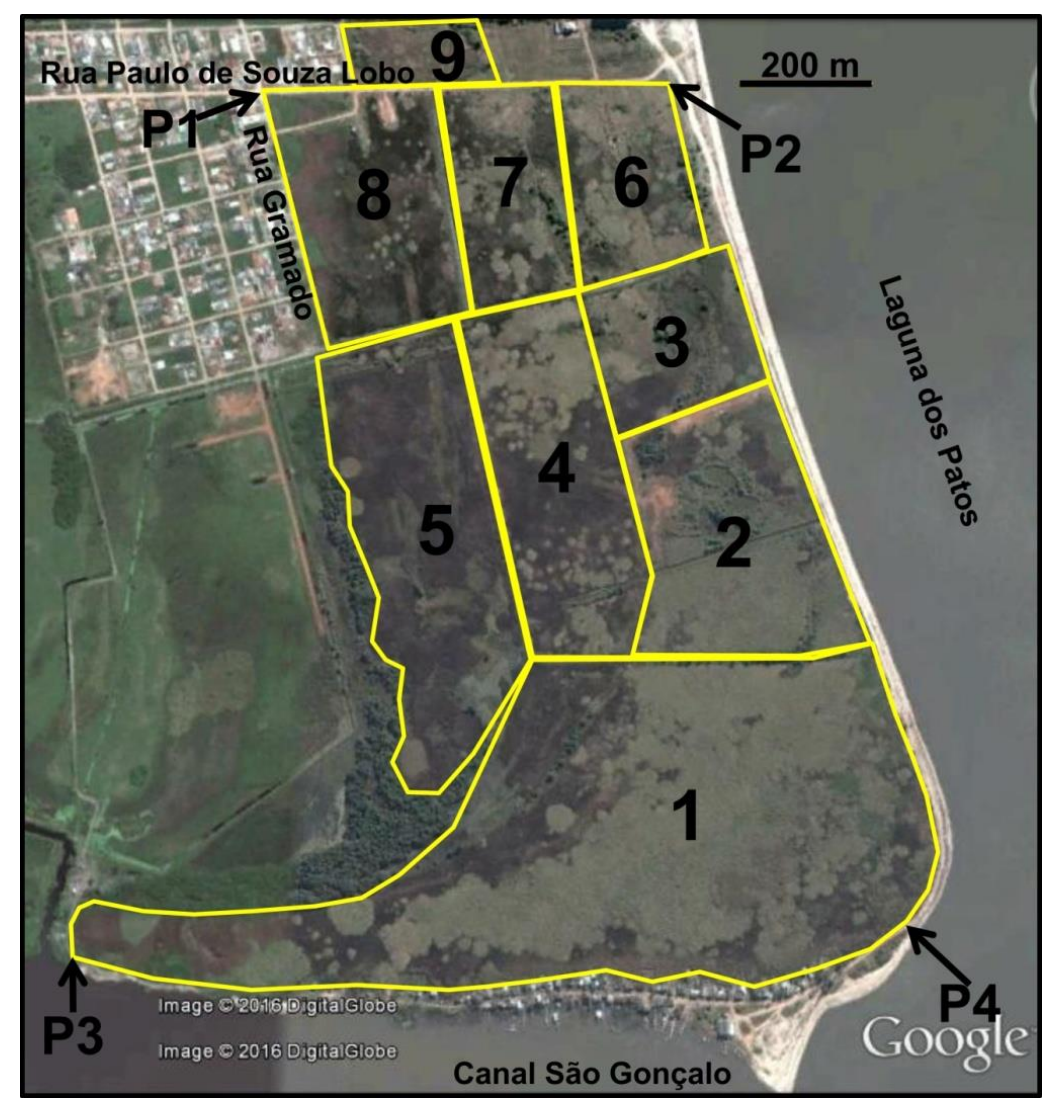

Setores 1 a 9. Pontos georreferenciados: P1, esquina das ruas Paulo Lobo e Gramado:

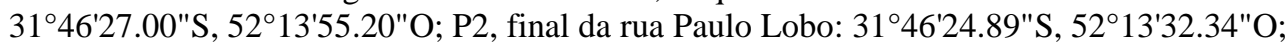
P3, extremo sudoeste: $31^{\circ} 47^{\prime} 9.89 " \mathrm{~S}, 52^{\circ} 14^{\prime} 1.54^{\prime \prime O}$; P4, curva do Pontal da Barra: $31^{\circ} 47^{\prime} 5.38^{\prime \prime S}, 52^{\circ} 13^{\prime} 15.64^{\prime \prime O}$. Fonte: Google Earth (editado pelos autores). 
Com base nos trabalhos de campo e na aplicação dos critérios aqui adotados, foi possível caracterizar os nove setores da seguinte forma:

A) Todos são "extensões de terras normalmente saturadas de água onde se desenvolvem fauna e flora típicas", preenchendo plenamente a definição de banhado da Lei 11.520/2000. Adicionalmente, cumpre salientar que todos os setores são total ou predominantemente cobertos de lâmina d'água por mais de 180 dias contínuos (normalmente, por mais de 250 dias), em todos os anos, conforme observações em campo conduzidas na área.

B) Particularidades de cada um dos nove setores de banhado são descritas abaixo, incluindo detalhamento sobre a ocorrência das espécies da fauna consideradas aqui como indicadores de banhado:

Setor 1: Existem estreitas faixas de campo inundável na porção noroeste do setor. Austrolebias nigrofasciatus, A. wolterstorffi e Limnornis curvirostris ocorrem amplamente no mesmo.

Setor 2: Uma faixa de banhado no norte desse setor foi aterrada. A margem oeste do setor contém parte de uma paleo-linha de praia que percorre o banhado de norte a sul (vide CHEFFE et al, 2016), ao longo da qual há ambientes de charcos temporários e um pequeno capão de mata nativa. Austrolebias nigrofasciatus e Limnornis curvirostris ocorrem amplamente nesse setor, ao passo que A. wolterstorffi ocorre pontualmente.

Setor 3: O centro desse setor apresenta um segmento da paleo-linha de praia, no qual há um grande charco temporário. Austrolebias nigrofasciatus, A. wolterstorffi e Limnornis curvirostris ocorrem amplamente nesse setor.

Setor 4: Austrolebias nigrofasciatus e Limnornis curvirostris ocorrem amplamente nesse setor.

Setor 5: Existem algumas pequenas ilhas naturais de campo na parte sul desse setor. Austrolebias nigrofasciatus, A. wolterstorffi e Limnornis curvirostris ocorrem amplamente nesse setor.

Setor 6: Cerca de 2 hectares de banhado da margem norte desse setor encontram-se aterrados. Esse setor inclui a ponta norte da paleo-linha de praia mencionada acima, onde há um charco temporário. Austrolebias nigrofasciatus, A. wolterstorffi e Limnornis curvirostris ocorrem nesse setor.

Setor 7: Cerca de 1 hectare de banhado da margem norte desse setor foi aterrada. O setor inclui a margem noroeste da paleo-linha de praia já mencionada, onde há trecho de charco 
temporário e faixa de mata nativa. Austrolebias nigrofasciatus, A. wolterstorffi e Limnornis curvirostris ocorrem nesse setor.

Setor 8: A margem oeste desse setor confina diretamente com a área urbanizada do loteamento do Pontal da Barra (ruas Paulo Lobo e Gramado; figura 3), e apresenta em sua faixa norte alguns aterros. Austrolebias nigrofasciatus, A. wolterstorffi e Limnornis curvirostris ocorrem amplamente nesse setor.

Setor 9: Austrolebias nigrofasciatus, A. wolterstorffi e Limnornis curvirostris ocorriam nesse setor, mas sua presença atual é incerta.

Cumpre mencionar que os charcos temporários, mencionados acima, também se enquadram na definição de banhado da Lei 11.520/2000. Diferem dos banhados extensos por serem espacialmente mais restritos, e por terem menos vegetação emergente.

Figura 3 - Espécies indicadoras ou típicas de banhado

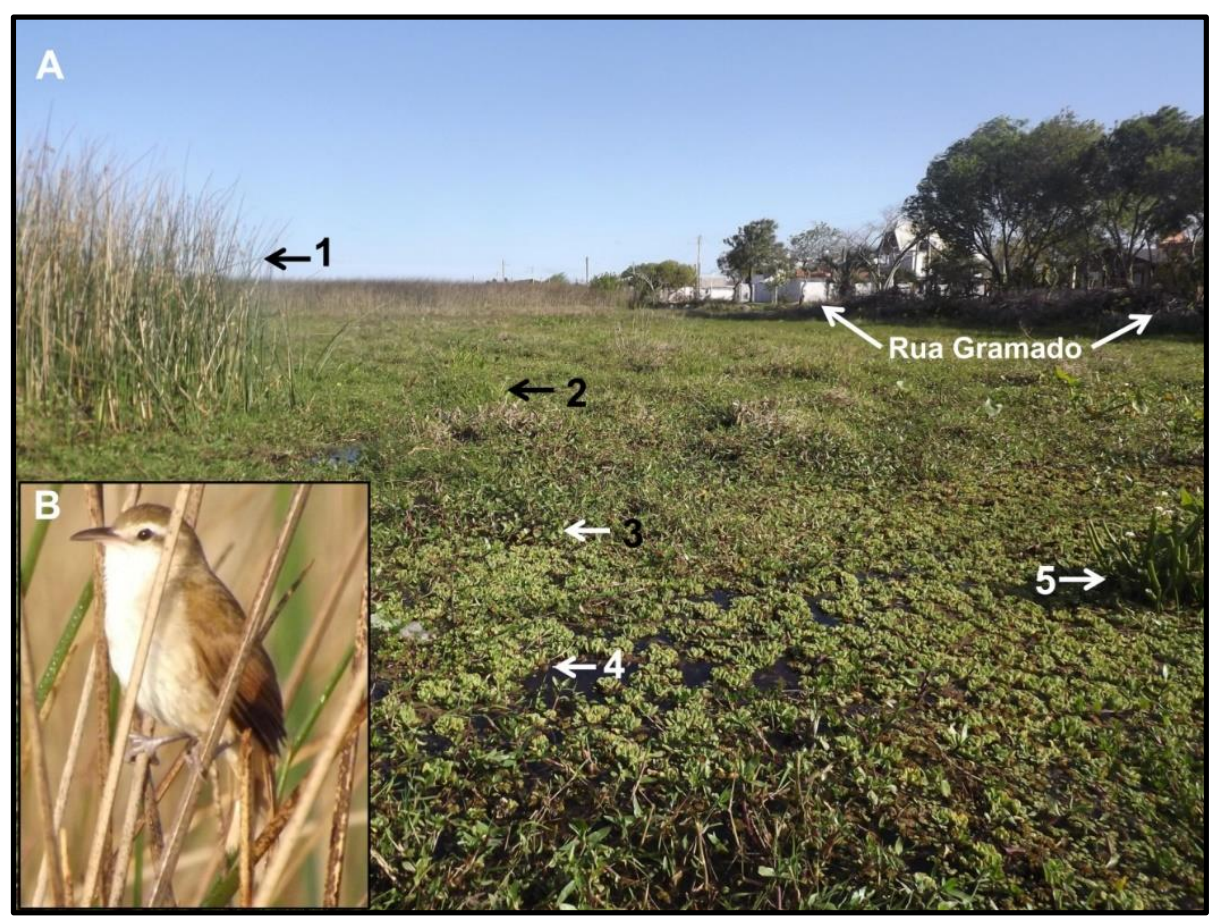

A. Trecho de banhado junto às ruas Gramado e Paulo Lobo (loteamento Pontal da Barra), no setor 8 da figura 2. As plantas indicadas por setas são: 1, Schoenoplectus californicus; 2, Pontederia lanceolata; 3, Eichhornia crassipes; 4, Pistia atratiotes; 5, Sagittaria montevidensis. Esse trecho de banhado é área de ocorrência e reprodução dos peixes anuais Austrolebias nigrofasciatus e A. wolterstorffi. B. Limnornis curvirostris (joão-da-palha), fotografado no setor 8. Fonte: Giovanni N. Maurício.

C) Em todos os setores, várias das espécies da fauna mencionadas no decreto do CAR são encontradas, a saber: Ardea alba (garça-branca-grande), Gallinula galeata e $G$. melanops (frango-d'água), Pomacea canaliculata (caramujo), Rostrhamus sociabilis (gavião-caramujeiro), Jacana jacana (jaçanã), Amazonetta brasiliensis (marreca-de-pé- 
vermelho), Amblyramphus holosericeus (cardeal-do-banhado), Myocastor coypus (ratãodo-banhado) e Hydrochoerus hydrochaeris (capivara). Já Caiman latirostris (jacaré-depapo-amarelo), Chauna torquata (tachã) e Ciconia maguari (joão-grande) têm sido detectados somente no setor 1 .

D) Um grande número de espécies de aves típicas de banhados, além das mencionadas acima, foi identificado em todos os setores aqui definidos, tais como: Botaurus pinnatus (socó-boi-baio), Pardirallus sanguinolentus (saracura-do-banhado), Cranioleuca sulphurifera (arredio-do-papo-manchado) e Tachuris rubrigastra (papa-piri). Contudo, todas essas espécies podem ocorrer em campos alagados ou em áreas pantanosas não naturais, como reservatórios com água rasa (açudes e represas antigos) tomados por juncais, não sendo, portanto, indicadores adequados para a presença de banhados. Limnornis curvirostris (joão-da-palha), pelo contrário, é considerado um especialista de hábitat, sendo encontrado exclusivamente em banhados com ciperáceas e outras plantas aquáticas emergentes (ACCORDI; HARTZ, 2006).

Tabela 1 - Relação de espécies da flora, comumente encontradas no banhado do Pontal da Barra, Pelotas, RS. Os setores de coleta estão ilustrados na figura 2.

\begin{tabular}{|c|c|c|c|}
\hline Nome científico & Nome popular & $\begin{array}{l}\text { Família } \\
\text { botânica }\end{array}$ & $\begin{array}{l}\text { Setor do } \\
\text { banhado }\end{array}$ \\
\hline Typha domingensis Pers. & taboa & Typhaceae & $1,2,5,6,7,8,9$ \\
\hline $\begin{array}{l}\text { Pistia stratiotes } \mathrm{L} . \\
\text { Schoenoplectus californicus }\end{array}$ & repolho-d'agua & Araceae & $1,2,3,4,6,7,8,9$ \\
\hline (C.A.Mey.) Steud. & junco & Cyperaceae & $1,2,3,4,5,6,7,8,9$ \\
\hline $\begin{array}{l}\text { Pontederia lanceolata Nutt. } \\
\text { Sagittaria montevidensis Cham. \& }\end{array}$ & aguapé & Pontederiaceae & $3,4,6,7,8,9$ \\
\hline Schl. & chapéu-de-couro & Alismataceae & $1,2,3,4,6,7,8,9$ \\
\hline Myriophyllum brasiliense Camb. & pinheirinho-d'água & Halorrhagaceae & $1,2,3,4,6,7,8$ \\
\hline $\begin{array}{l}\text { Salvinia auriculata Aubl. } \\
\text { Eichhornia crassipes (Mart.) Solms.- }\end{array}$ & alface-de-água & Salvinaceae & $1,2,3,4,6,7,8,9$ \\
\hline Laubach & aguapé & Pontederiaceae & $2,3,6,7,8$ \\
\hline Scirpus giganteus Kunth & tiririca & Cyperaceae & $1,2,3,4,5,6,7,8,9$ \\
\hline Azolla filiculoides Lam. & murere rendado & Salvinaceae & $3,4,7,8,9$ \\
\hline Polygonum punctatum & $\begin{array}{l}\text { pimenta-d'água } \\
\text { margarida-do- }\end{array}$ & Polygonaceae & $1,2,3,6,7,8,9$ \\
\hline Senecio bonariensis Hook \& Arn. & banhado & Asteraceae & $1,2,3,9$ \\
\hline $\begin{array}{l}\text { Mimosa bimucronata (DC.) Kuntze } \\
\text { Zizaniopsis bonariensis (Balansa \& }\end{array}$ & maricá & Fabaceae & $2,4,6,7,9$ \\
\hline Poitr.) Speg & espadana & Poaceae & $1,2,3,4,5,6,7,8$ \\
\hline Erythrina crista-galli L. & corticeira-do-banhado & Fabaceae & $1,2,3,4,7$ \\
\hline
\end{tabular}

Fonte: os autores 
E) Em todos os setores, estão presentes várias espécies da flora típicas de banhado (Tabela 1). Foram observadas as espécies dominantes típicas da vegetação dos banhados do Rio Grande do Sul, como Typha domingensis, Schoenoplectus californicus, Scirpus giganteus e Zizaniopsis bonariensis. Esta última foi documentada no município de Pelotas somente no Pontal da Barra, o que salienta a importância ambiental do local. Muitas outras plantas típicas de banhados são encontradas no Pontal da Barra, como as plantas flutuantes Pistia stratiotes e Salvinia auriculata. Estes vegetais crescem flutuando na água e livres entre as plantas dominantes do banhado.

F) Os solos no Pontal da Barra foram classificados conforme o manual de campo dos Solos do Rio Grande do Sul (STRECK et al., 2008 ). São encontrados no local os solos Chernossolo Argilínico Carbonático e Gleissolos Haplicos Eutróficos. Os solos do tipo Chernossolo Argilínico Carbonático são solos que ocorrem em relevo plano e com drenagem imperfeita. Já os solos do tipo Gleissolos Haplicos Eutróficos, são denominados pelo processo de gleização, que é a dissolução do ferro, e este processo ocorre em ambientes alagadiços. Em resumo, os solos do Pontal da Barra são encharcados normalmente todo o período do ano e característicos dos banhados do Estado do Rio Grande do Sul.

\section{3 - Conclusões}

De acordo com os critérios considerados no presente trabalho, todos os setores definidos na figura 2 representam, em grande parte ou em sua totalidade, áreas de banhado, como exemplificado na figura 3. Esse enquadramento como banhado resultou da aplicação dos seguintes critérios ou instrumentos legais: (1) o conceito constante do Código Estadual do Meio Ambiente (Lei Estadual $n^{\circ} 11.520$ ); (2) o conceito mais rigoroso constante do decreto do CAR (Decreto Estadual $n^{\circ}$ 52.431); e (3) o uso de indicadores biológicos rigorosamente escolhidos (duas espécies de peixes e uma de ave), cuja presença sustenta tecnicamente a identificação dos setores como áreas de banhado.

A identificação dos setores elencados neste estudo (1 a 9) como outro ambiente que não banhado gera uma inconsistência de grande magnitude em relação a outros casos em que a FEPAM (Fundação Estadual de Proteção Ambiental) identificou ambientes alagados como banhados e, justamente por essa identificação, determinou que estes deveriam ser preservados. Um exemplo recente de tal situação ocorreu com a área da Chácara da Brigada, às margens do arroio Pelotas. A FEPAM negou licença prévia por considerar 
que a poligonal requerida para instalação de empreendimento industrial era área de banhado e, por conseguinte, seria uma Área de Preservação Permanente (Diário Popular, 23 de agosto de 2016, p. 7).

Propõe-se que os setores 1 a 9 aqui discutidos, se desqualificados como áreas banhado por órgãos ambientais, que a justificativa para tal desqualificação venha acompanhada de dados concretos e argumentação científica robusta, abordando e refutando cada um dos critérios estabelecidos no presente estudo.

\section{REFERÊNCIAS}

ACCORDI, I. A.; HARTZ, S. M. Distribuição espacial e sazonal da avifauna em uma área úmida costeira do sul do Brasil. Revista Brasileira de Ornitologia, São Leopoldo, v. 14, nº 02, p. 117-135, Junho, 2006.

BRASIL. Portaria no 445, de 17 de dezembro de 2014. Ministério do Meio Ambiente. Diário Oficial da União, Brasília, 18 de dezembro de 2014, nº 245, p. 126-130.

BRASIL. Lista nacional oficial de espécies da flora ameaçadas de extinção, publicada no Diário Oficial da União em 18 de dezembro de 2014." Disponível em http://www.icmbio.gov.br/cepsul/images/stories/legislacao/Portaria/2014/p_mma 443 2014_lista_esp\%C3\%A9cies_amea\%C3\%A7adas_extin\%C3\%A7\%C3\%A3o.pdf

CHEFFE, M. M.; MAURÍCIO, G. N.; LOPES, A. L. O. O Impacto ambiental sobre as populações de Austrolebias (Pisces: Cyprinodontiformes: Rivulidae) com a construção de um dique de contenção no banhado do Pontal da Barra, Pelotas, RS. Revista Geographia Meridionalis, Pelotas, v. 02, nº 01, p.145-152, Jan/Jun. 2016.

CORDAZZO, C. V,; SEELIGER, U. . Guia ilustrado da vegetação costeira no Extremo Sul do Brasil. Rio Grande: Editora FURG, 1995. 275p.

CORDAZZO, C. V.; PAIVA, J. B.; SEELIGER, U. Guia ilustrado das plantas das dunas da costa sudoeste Atlântica. Pelotas: USEB, 2006. 107 p. (Manuais de Campo USEB, 8).

COSTA, W. J. E. M.; CHEFFE, M. M. Three new annual fishes of the genus Austrolebias from the laguna dos Patos system, southern Brazil, and a redescription of A. adloffii (Ahl) (Cyprinodontiformes: Rivulidae). Comunicações do Museu de Ciências e Tecnologia da PUCRS, série Zoologia, Porto Alegre, v. 14, p. 179-200, 2001. 
EIA (ESTUdo DE IMPACTO AMBIENTAL). Pontal da Barra. Pelotas: Aquasan, 1990.

FONTANA, C. S.; BENCKE, G. A.; REIS, R. E. (Orgs.). Livro Vermelho da Fauna Ameaçada de Extinção do Rio Grande do Sul. Porto Alegre: Edipucrs, 2003. 632 p.

ICZN (International Commission on Zoological Nomenclature). International Code of Zoological Nomenclature, Fourth Edition. International Trust for Zoological Nomenclature, London, xxix + 306 pp., 1999.

IRGANG, B. E.; GASTAL, C. V. S. Macrófitas aquáticas da Planície Costeira do RS. Porto Alegre: Edição dos Autores. 1996.

MILHEIRA, R. G.; CERQUEIRA, F. V.; ALVES, A. G. Programa arqueológico de diagnóstico e prospecção na região do Pontal da Barra, Pelotas - RS. Revista Memória em Rede, Pelotas, v. 2, nº 7, p. 1-27, Jul/Dez. 2012.

Ministério PÚbliCO FEDERAL. Ação Civíl Pública, Pontal da Barra. Pelotas: Procuradoria da República no Estado do Rio Grande do Sul / Procuradoria da República no Município de Pelotas. 2012.

RIO GRANDE DO SUL. Lei $\mathbf{n}^{\mathbf{0}}$ 11.520/2000. Institui o Código Estadual do Meio Ambiente do Estado do Rio Grande do Sul e dá outras providências. Assembleia Legislativa, Estado do Rio Grande do Sul. 2000.

RIO GRANDE DO SUL. Decreto Estadual no 51.79708, de 08 setembro de 2014. Declara as espécies da fauna silvestre ameaçadas de extinção no Rio Grande do Sul. Diário Oficial, Porto Alegre, 09 de setembro de 2014, p. 2-12.

RIO GRANDE DO SUL. Decreto Estadual no 52.431, de 23 de junho de 2015. Dispõe sobre a implementação do Cadastro Ambiental Rural e define conceitos e procedimentos para a aplicação da Lei Federal $n^{\circ} 12.651$, de 25 de maio de 2012, no Estado do Rio Grande do Sul. Diário Oficial, Porto Alegre, 23 de junho de 2015.

SELMO, F. S.; ASMUS, M. L. Análise ambiental da ocupação urbana do Pontal da Barra, praia do Laranjal, Pelotas, RS. Cadernos de Ecologia Aquática, Rio Grande, v. $01, n^{\circ} 2$, p. 30-37, 2006.

SILVA, A. R. E., et al. Nota técnica referente à construção do dique de contenção no Pontal da Barra, Laranjal (Pelotas, RS). Revista Geographia Meridionalis, Pelotas, v. 01, nº 02, p.412-418, Jul/Dez. 2015.

STRECK, E. V.; KÄMPF, N.; DALMOLIN, R. S. D.; KLAMT, E.; NASCIMENTO, P. C.; SCHNEIDER, P.; GIASSON, E.; PINTO, L. F. P. Solos do Rio Grande do Sul. $2^{\text {a }}$ Ed.. Porto Alegre: Emater/RS. 2008. V. 1. 
TASSI, R.; MARQUES, D. M.; COLLISCHONN, W. Advances in water management of southern Brazilian sub-tropical wetlands using bio-indicators. Changes in Water Resources Systems: Methodologies to Maintain Water Security and Ensure Integrated Management (Proceedings of Symposium HS3006 at IUGG2007, Perugia, July 2007). IAHS Publ. 315, 2007. 